\title{
POSITIVE SOLUTIONS OF A SYSTEM OF FRACTIONAL FUNCTIONAL DIFFERENTIAL EQUATIONS WITH NONLOCAL BOUNDARY CONDITIONS
}

\section{SVATOSLAV STANĚK}

Abstract. We study the system of two fractional functional differential equations with the Caputo fractional derivative. Using the Guo-Krasnoselskii fixed point theorem on cones and the nonlinear Leray-Schauder alternative the existence of positive solutions to the system satisfying nonlocal boundary conditions is proved. The boundary conditions are given by linear bounded functionals. Examples are given to illustrate our results.

Mathematics subject classification (2010): 34A08, 26A33, 33E12, 34B18.

Keywords and phrases: Fractional functional equation, nonlocal boundary condition, Caputo fractional derivative, Guo-Krasnoselskii fixed point theorem, nonlinear Leray-Schauder alternative, positive solution.

\section{REFERENCES}

[1] B. AhmAd, S. K. NTOUYAS AND A. AlS AEDI, On a coupled system of fractional differential equations with coupled nonlocal and integral boundary conditions, Chaos Solitons Fractals, 83 (2016), 234-241.

[2] K. Deimling, Nonlinear Functional Analysis, Springer, Berlin, 1985.

[3] K. Diethelm, The Analysis of Fractional Differential Equations, Lectures Notes in Mathematics, Springer Berlin Heidelberg 2010.

[4] D. Guo And V. Lakshmikantham, Nonlinear Problems in Abstract Cones, Academic Press, New York, 1988.

[5] J. HENDERSON AND R. LUCA, Nonexistence of positive solutions for a system of coupled fractional boundary value problems, Bound. Value Probl. (2015) 2015:138 DOI 10.1186/s13661-015-0403-8

[6] J. Henderson AND R. LuCA, Positive solutions for a system of semipositone coupled fractional boundary value problems, Bound. Value Probl. (2016) 2016:61 DOI 10.1186/s13661-016-0569-8

[7] D. Henry, Geometric Theory of Semilinear Parabolic Equations, Lectures Notes in Math., vol. 840, Springer, Berlin-New York, 1989.

[8] A. A. Kilbas, H. M. SRivastava And J. J. Trujillo, Theory and Applications of Fractional Differential Equations, Elsevier B. V., Amsterdam, The Netherlands, 2006.

[9] Y. Li, Y. SANG AND H. Zhang, Solvability of a coupled system of nonlinear fractional differential equations with fractional integral conditions, J. Appl. Math. Comput, (2016) 50:73-91 DOI 10.1007/s12190-014-0859-1

[10] P. Li, H. WANG AND Z. LI, Infinitely many solutions to boundary value problems for a coupled system of fractional differential equations, J. Nonlinear Sci. Appl. 9 (2016), 3433-3444.

[11] S. N. RAO, Existence and multiplicity for a system of fractional higher-order two-point boundary value problem, J. Appl. Math. Comput, (2016) 51:93-107 DOI 10.1007/s12190-015-0893-7

[12] K. SHAH AND R. A. KHAN, Existence and uniqueness of positive solutions to a coupled system of nonlinear fractional order differential equations with anti periodic boundary conditions, Differ. Equ. Appl. 7, 2 (2015), 245-262.

[13] K. Shah, A. Ali And R. A. Khan, Degree theory and existence of positive solutions to coupled systems of multi-point boundary value problems, Bound. Value Probl. (2016) 2016:43 DOI $10.1186 / \mathrm{s} 13661-016-0553-3$ 
[14] H. ZHANG, Y. LI AND W. LU, Existence and uniqueness of solutions for a coupled system of nonlinear fractional differential equations with fractional integral boundary conditions, J. Nonlinear Sci. Appl. 9 (2016), 2434-2447.

[15] Y. ZHAO, H. CHEN AND B. QIN, Multiple solutions for a coupled system of nonlinear fractional differential equations wia variational methods, Appl. Math. Comp. 257 (2015), 417-427.

[16] D. ZHAO AND Y. LiU, Positive solutions for a class of fractional differential coupled system with integral boundary value conditions, J. Nonlinear Sci. Appl. 9 (2016), 2922-2942. 